Purdue University

Purdue e-Pubs

Charleston Library Conference

\title{
An Evolving Model for Consortial Print and E-Book Collections: Triangle Research Libraries Network, Oxford University Press, YBP Library Services Pilot
}

\author{
Ann-Marie Breaux \\ YBP Library Services, abreaux@ybp.com \\ Lisa Croucher \\ Triangle Research Libraries Network (TRLN), lisa@trln.org \\ Teddy Gray \\ DukeUniversity, teddy.gray@duke.edu \\ Cotina Jones \\ North Carolina Central University, cjone104@nccu.edu \\ Rebecca Seger \\ Oxford University Press, Rebecca.Seger@oup.com \\ Seronexthpage for rafdlitionalarkthor:Sttps://docs.lib.purdue.edu/charleston \\ Part of the Library and Information Science Commons \\ An indexed, print copy of the Proceedings is also available for purchase at: \\ http://www.thepress.purdue.edu/series/charleston. \\ You may also be interested in the new series, Charleston Insights in Library, Archival, and Information \\ Sciences. Find out more at: http://www.thepress.purdue.edu/series/charleston-insights-library-archival- \\ and-information-sciences.
}

Ann-Marie Breaux, Lisa Croucher, Teddy Gray, Cotina Jones, Rebecca Seger, and Luke Swindler, "An Evolving Model for Consortial Print and E-Book Collections: Triangle Research Libraries Network, Oxford University Press, YBP Library Services Pilot" (2013). Proceedings of the Charleston Library Conference. http://dx.doi.org/10.5703/1288284315248

This document has been made available through Purdue e-Pubs, a service of the Purdue University Libraries. Please contact epubs@purdue.edu for additional information. 


\section{Presenter Information}

Ann-Marie Breaux, Lisa Croucher, Teddy Gray, Cotina Jones, Rebecca Seger, and Luke Swindler 


\title{
An Evolving Model for Consortial Print and E-Book Collections: Triangle Research Libraries Network, Oxford University Press, YBP Library Services Pilot
}

\author{
Ann-Marie Breaux, Vice President, Academic Service Integration, YBP Library Services \\ Lisa Croucher, Program Officer, Triangle Research Libraries Network (TRLN) \\ Teddy Gray, Interim Head of Collection Development, Duke University Libraries \\ Cotina Jones, Assistant Director of Library Services, North Carolina Central University Library \\ Rebecca Seger, Director of Institutional Sales-Americas, Oxford University Press \\ Luke Swindler, Collections Management Officer, University of North Carolina at Chapel Hill
}

\begin{abstract}
The Triangle Research Libraries Network (TRLN) and Oxford University Press (OUP) are continuing their pilot to create a financially sustainable model for consortial acquisition of e-books coupled with needed shared print copies in cooperation with YBP Library Services (YBP). The project expands acquisitions of e-books in tandem with reductions in print, so as to move both the consortium and the university presses to a decidedly electronic environment for books that will enhance support for instruction and research across the disciplinary spectrum within an environment that is acceptable to users. This paper reports on the challenges and lessons learned in Year 1, librarian and patron reactions to this format shift, and the resulting philosophical and practical evolutions in TRLN's approaches to monographic acquisitions generally and understandings of what constitutes cooperative success specifically. The paper also discusses how this knowledge has changed understandings about vending and acquiring e-books and their relationship to print, and what have been the implications of these experiences for making changes in Year 2 and envisioning how the pilot would become a permanent venture.
\end{abstract}

\section{Background}

The Triangle Research Libraries Network (TRLN) is a collaborative organization consisting of Duke University, North Carolina Central University, North Carolina State University, and the University of North Carolina at Chapel Hill. Its purpose is to marshal the financial, human, and information resources of their research libraries through cooperative efforts in order to create a rich and unparalleled knowledge environment that furthers the universities' teaching, research, and service missions.

TRLN has a long history of cooperative collection development going back decades that distribute subject and language responsibilities among member libraries to minimize overlap and maximize breadth of coverage. Higher e-book prices for single institutions and weighty multipliers to enable interinstitutional access threaten this investment and the future of scholarly sharing.
In August 2011, TRLN hosted the Beyond Print Summit as a culminating event of the Beyond Print project, funded by the Andrew W. Mellon Foundation to develop new business models and licensing terms for the cooperative acquisition of e-books. A key element of the project was to convene representatives from library consortia, together with vendors and publishers, to explore new and mutually sustainable models as research libraries make the transition from print to electronic in their book collections. The TRLN Beyond Print Summit included participation by representatives of Oxford University Press and YBP Library Services.

A primary outcome of the Beyond Print Summit was the TRLN/Oxford University Press (OUP)/YBP Consortial E-Books Pilot which attempts to create a financially sustainable model for consortial acquisition of e-books, with parallel acquisition of print copies as needed. During the pilot, which runs May 2012 through April 2014, TRLN acquires nearly the entire monographic output of OUP and partner presses on the University Press 
Scholarship Online (UPSO) platform as either ebooks with unlimited simultaneous users or as single shared print copies.

\section{Year 1: TRLN Perspective}

TRLN's goals for this pilot include maximizing support for the academic enterprise; creating a model for consortial acquisition of e-books coupled with needed print that is acceptable to users; shifting libraries and partner publishers to a decidedly electronic environment for monographs; developing a flexible vending framework for systematically increasing e-books acquisitions in tandem with reducing print intake, while keeping net costs constant and therefore sustainable over time; and developing a model that is not merely a "buying club," which other library consortia and publishers may find useful and adaptable.

The project allows TRLN to acquire the entire monographic output of core publishers, with each campus individually and separately owning every e-book on the UPSO platform. TRLN collectively owns at least a single shared print copy of nearly every title from these publishers not on the UPSO platform and selectively duplicates with shared print some titles in humanities and social sciences also available as e-books. The model is not designed to reduce the level of acquisitions or save money by cutting aggregate monographic expenditures. The pilot also relies on shared vendor (YBP) to manage costs and content and (for print) provide shelf-ready processing.

From the TRLN perspective, the first year of the pilot was not without challenges, most of which were operational. For example, the delivery time of shared print books from the Library Service Center to the patron initially was longer than acceptable given the initial design of the workflow, and the creation of MARC records and curation of materials was not as efficiently cooperative as had been envisioned.

Administrators of the pilot played an important ambassadorial role with their colleagues, educating them about the challenges and benefits of cooperation and allaying fears of negative user reactions (few of which were realized). They also had to deal with ongoing frustration and confusion inherent in the still imperfect vending mechanisms for e-books, especially those related to lack of clarity about which titles would come in which format and when.

Cooperation in a digital world fundamentally inverts the metric for success from uniqueness of titles held to extensiveness of duplication within the consortium. A librarian at North Carolina Central University noted her particular appreciation of the diversity of subjects available immediately, on the UPSO platform, especially given that the university would not ordinarily have been able to afford such a vast collection.

This pilot has revealed that a critical difference exists between what patrons might prefer in theory and what they will accept in reality. Specifically patrons will accept e-only or shared print located offsite with quick delivery so long as key titles are held locally. Within this context, the pilot has provided much useful information about how patrons use e-books and print, both absolutely and in relation to each other, as the figures at the end of this paper illustrate.

Librarians also learned that given acceptable inflection points, an optimal consortial solution for key publishers would be both "just in case" (broad, en bloc acquisitions for electronic) and "just in time" (narrow, evidence-based acquisitions for print), with any delays in print being made acceptable in part by availability of electronic.

\section{Year 1: OUP Perspective}

During the first year of the pilot, both OUP and the TRLN libraries gleaned a better understanding of acquisitions issues from each other's perspectives. Both recognized the need for advance title data and the confusion caused on 


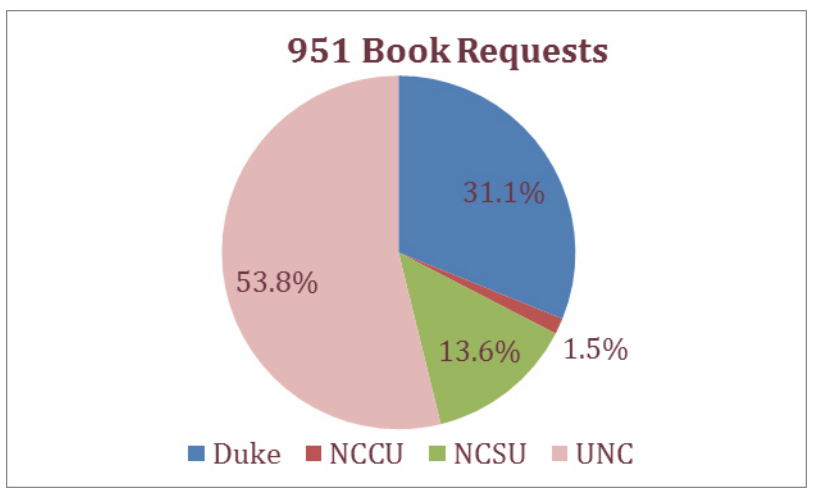

Figure 1. Print Requests by School (Year 1)

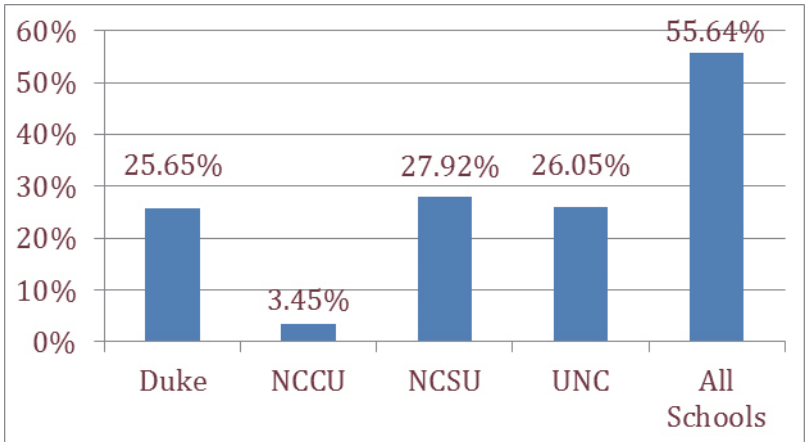

Figure 3. E-Book Title Usage (Year 1)

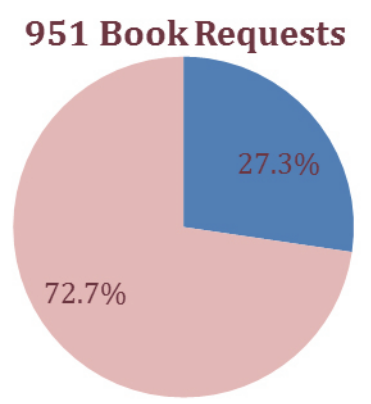

E-Book Available E-Book Not Available

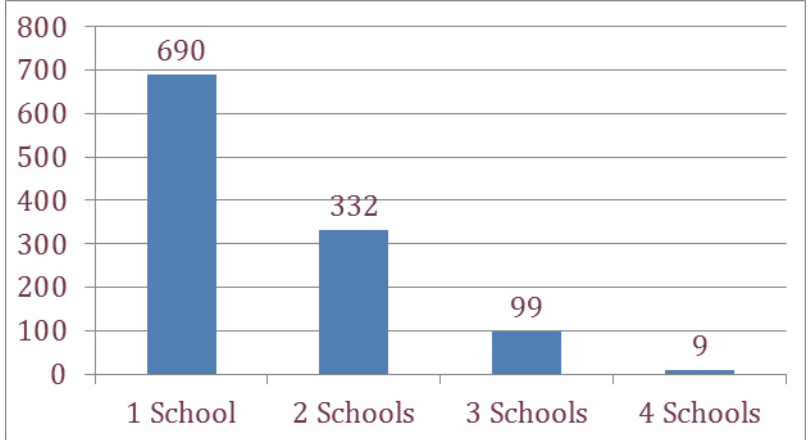

Figure 4. Unique E-Book Title Usage (Year 1)

\section{8,797 Chapters Downloaded}

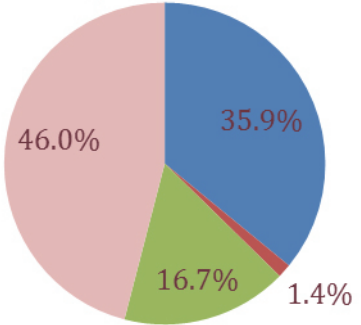

Duke $\square$ NCCU $\square$ NCSU $\square$ UNC

Figure 5. E-Book Section Usage (Year 1)

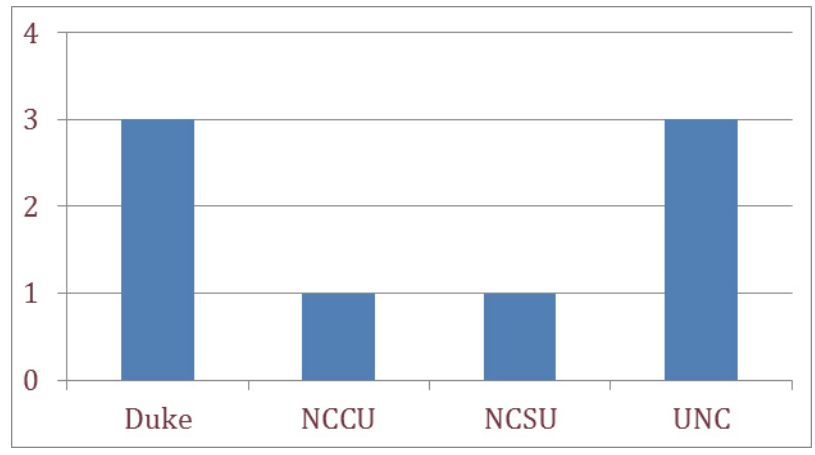

Figure 6. Median Downloads Per E-Book (Year 1) 


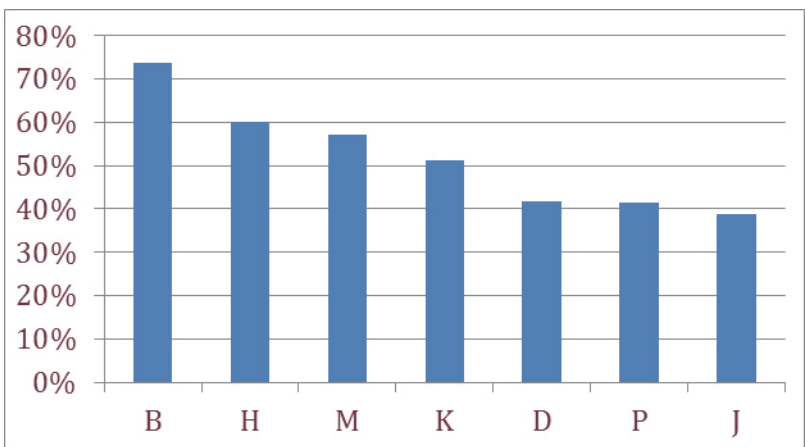

Figure 7. E-Book Title Usage by Library of Congress Class (Year 1)

the part of librarians by delays between the availability of print and electronic materials.

The print output fluctuated more than anyone expected. As a result, print costs were difficult to manage, especially those related to multiple copy discounts (beyond the first shared print copy), which were deemed not necessary to the sustainability of the pilot given the administrative complexity. OUP noted that the key to collaboration is honest and open dialogue with the libraries about sustainability for all parties, and what constitutes sustainability across a broad range of book publishing: monograph, trade, course adoption, third party rights issues.

\section{Year 1: YBP Perspective}

YBP sent the first invoice for electronic books on May 1, 2012, for quarterly releases in May, July, September, and January, for a total of 150 packages (2,015 titles). Ten university presses were included: American/Cairo, California, Edinburgh, Florida, Fordham, Hong Kong, Kentucky, Manchester, Oxford, and Policy. The first invoice for print, which is managed by UNCChapel Hill, was sent on May 25, 2012, for 2,809 titles (reduced from 3,137).

All participants understood and agreed that the purpose of the pilot was to learn. A major lesson realized in Year 1 was the importance of establishing a thorough and complete agreement about content and operations. The reduction in number of print titles was due, in part, to lack of consistent understanding across OUP, TRLN, and YBP of the print content included in the pilot.

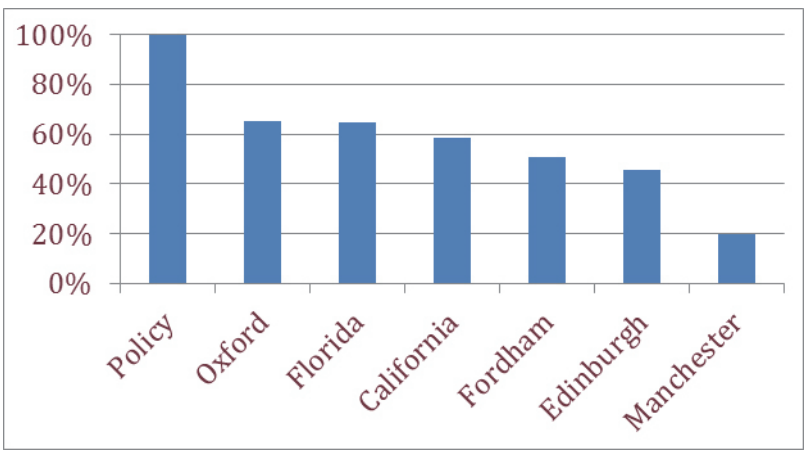

Figure 8. E-Book Title Usage by Publisher (Year 1)

Other lessons learned included the importance of simplified processes for duplication control, that slips for UPSO titles may be confusing for library selectors, and that past publishing output may not accurately predict future publishing output. Each of these issues is being addressed in Year 2.

\section{Year 2 and Beyond: TRLN Perspective}

Collection and analysis of evaluative data from Year 1 (May 2012-April 2013) of the pilot is ongoing. Overall, TRLN was pleased with the pilot, with the service provided by OUP and YBP, and with efforts on the part of OUP and YBP to accommodate TRLN requests and collaboratively pursue project goals.

On the basis of an interim evaluation, TRLN, OUP, and $Y B P$ agreed to continue the pilot for a second year. During Year 2, TRLN will acquire more ebooks and fewer print books in order to keep costs constant, having adjusted for the increased number of publishers (from ten in Year 1, to 15 in Year 2) and availability of more e-books in more subject packages.

Before the pilot, of the titles acquired by TRLN from publishers included in the pilot, fewer than $1 \%$ of the copies were e-books. After Year 1, of the titles acquired by TRLN from the publishers included in the pilot, $74 \%$ of the copies were ebooks. We project that in Year 2, 81\% of titles from these publishers will be e-books.

Looking further ahead, TRLN is considering how a potential third year of the pilot might continue to be both beneficial and financially sustainable for all involved. TRLN also would consider applying 
this model to other publishers, perhaps even considering an e-only model with print copies being purchased only on demand.

\section{Year 2 and Beyond: OUP Perspective}

The pilot has been expanded to include five additional UPSO partner presses: Liverpool University Press, MIT Press, Stanford University Press, University of Chicago Press, and Yale University Press. The frontlist print purchasing is being administered exclusively by YBP and TRLN, with no involvement from OUP.

As mentioned above, administrative complexity led to a decision between OUP and TRLN to no longer discount multiple copy print purchases. OUP continues to improve its data on forthcoming titles, increase the speed to market of electronic copies, and monitor usage as well as opportunities to assist libraries. Finally, OUP continues to expand the range of content available, ensuring the visibility of economic impact of the pilot.

\section{Year 2 and Beyond: YBP Perspective}

YBP has made enhancements to its consortial services based on TRLN review and other feedback. GOBI now indicates whether a title is print or electronic without a user's having to click on a link to get that information; GobiTween distinguishes between print and electronic titles; member library accounts now show consortial purchase details in real time; and duplication control has been improved within consortial groups or linked libraries.

TRLN and YBP worked to establish a more selective coverage of print (e.g., fewer subject areas, print spending cap) for Year 2 that does not guarantee $100 \%$ acquisition of publisher output across print and electronic. Like TRLN and OUP, YBP is considering whether it is possible to simplify the arrangement for a potential third year, without sacrificing the respective benefits for all participants. 